\title{
Effectiveness of the African Bereavement Counseling Techniques: A Case of Shona People of Zimbabwe: Implications for Open and Distance Learning Institutions
}

\author{
Shillah Rugonye \\ Zimbabwe Open University \\ Mashonaland East Region, Marondera \\ srugonye@gmail.com
}

\author{
Professor Richard Bukaliya \\ Zimbabwe Open University \\ Mashonaland East Region, Marondera \\ bukaliar@gmail.com
}

\begin{abstract}
This study was a qualitative case study on the effectiveness of the African bereavement counseling techniques on the Shona people of Zimbabwe. The study focused on one phenomenon that is, African bereavement counseling, so as to understand it in depth regardless of being other cultures in Africa. The participants for the study were drawn from the five wards in Marondera Urban. A sample of 20 participants was chosen through snowball sampling and these were subjected to interviews. The study noted that grieving people were affected with long term psychological consequences such as depression, anxiety, past traumatic stress disorder, behaviour problems, suicidal ideation and reduced psychological functioning. The study also established that African Bereavement counseling techniques were very effective in counseling the bereaved. The grieving styles can make one's bereavement burden easy. It was also established, however, that the Shona cultural ways of assisting the bereaved were not enough as they tended to bunch the adolescents to bottle up their emotions thus hastening their recovery. There is need for bereavement intervention programmes and ODL institutions, due to their geographical advantage, can be able to make provisions for counselling for those who suffer bereavement. ZOU through the Department of Counselling in the Faculty of Applied Social Sciences, can play a leading role through Programme Coordinators in the ten geo-political provinces. These can study the bereavement practices in their areas and find out ways of assisting those in moaning. Counselors should be multicultural when dealing with grieving issues. It is more therapeutic to help a client in his /her frame of reference thus in client's cultural setting. ZOU can play a role which could see the institution realising a major in terms of popularity which might translate to huge enrolment figures.
\end{abstract}

\section{INTRODUCTION}

It is common to mourn the death of a loved one and many countries have their own culturally creative expressions of grief. When people lose their beloved ones, they grieve and this affects them socially, physically and psychologically. Activities can range from somber memorial services to joyous celebrations and parties. For the most part, people are encouraged to show their grief when a loved one dies, besides sorrow, many may feel anger or guilt. Grief is an experience felt all over the world by people who have lost a loved one through death. The manner in which grieving takes place differs from culture to culture and Zimbabwe Shona culture is no exception. According to Strobe (1997), cited by Payne and Horn (1999), grief incorporates diverse psychological and physical symptoms. This means, when trying to assist the bereaved, both psychological and physical aspects must be considered. Grief can, however, become complicated (Prigerson et al. 1995; Stroebe et al. 2001; Worden 1991) and can lead to impaired social functioning.

Death has a devastating effect on both the dying and the bereaved. Prevalence of HIV/AIDS has led to increase in death rate and the need for various bereavement intervention programmes. When a loved one dies especially in Shona culture, adolescents are tasked to run the errands at the funeral, women if it's the death of a husband or husband the death of his wife, is expected to give an account on what led to the death of the husband to the relatives and vice versa. The husband or wife will be busy running around organizing the funeral arrangements. At times the one bereaved is subjected to inhabitation of grief as relatives take the forefront excluding the involvement of adolescents, wife or husband. As the wife /husband is left out in planning, he/she might be in a daze where he/she cannot concentrate and is anxious. These are normal responses to the shock and distress of the mind.

Failure to incorporate the bereaved in the proceedings of the funeral arrangements might hamper the bereaved from accepting the situation hence feelings of guilt and remorse are likely to torment the 
mind of the bereaved. It is against this background that the researchers undertook to assess the effectiveness of the African bereavement counseling techniques with special reference to the Shona people of Zimbabwe.

\section{RESEARCH QUESTIONS}

The study aimed at addressing the following research questions:

1. Do African bereavement counseling techniques assist the bereaved to avoid grieving and promote behavioural change?

2. What are the social effects of grief?

3. How do the bereaved perceive African bereavement counseling techniques?

4. How effective is the African bereavement counseling in helping the bereaved?

5. How can ODL institutions assist in the African bereavement counseling

\section{REVIEW OF RELATED LITERATURE}

\subsection{Conceptual Framework}

Grief is experienced by people in different ways. This is so because one's concept of death is based on one's concept of life Valente, Saunders and Street (1988). Some people become confused, disorganized or go into depression when they grieve for the death of the loved one. Death makes people realise their mortality and vulnerability as human beings (Chiremba and Makore-Rukuni, 2004). All the bereaved's belief about death will certainly reflect the uncertainity, ambiguity and inconsisteny of the cultural beliefs. The bereaved's grief has characteristics in common with both adult and childhood grief. Grief for adults usually consists of conflicted emotions of guilt, anger, powerlessness, withdrawal and isolation. The clinical symptoms of complicated grief include somatic distress, preoccupation with the image of the deceased, guilt, hostile reactions and loss of conduct previously influenced by the deceased (Vargas, Loya and Hodd-Vargas, 1989).

Cross-cultural studies look outward, seeking an opening to the varieties of cultural expression around the world. However, it also looks inward, because an understanding of others can enrich our understanding of our own culture. All people are shaped to some extent by the culture into which they are born. The human expression of grief is no less a product of culture than marital or religious customs or symbols. Many writers make a distinction between grief and mourning, saying that grief is a subjective state, a set of feelings that arise spontaneously after a significant death, whereas mourning is a set of rituals or behaviours prescribed by culture's tradition. In this distinction, thought, or cognitive meaning, is largely absent from both grief and mourning because the former is mostly feelings and the latter mostly action.

But this distinction between grief and mourning does not hold up to cross-cultural scrutiny. The concept of grief is an artifact of modernity. Grief as a real subjective state grows from a culture that prizes and cultivates individual experience. There is no equivalent to the term grief in some other languages; indeed, in some cultures, as in Japan, the concept of emotions that are only in the individual seems foreign. For the Japanese, individual identity is a function of social harmony. Emotions are part of family or community membership, sensed among the members so as to create a harmonized atmosphere.

At the biological level it might seem that grief is universal. In every culture people cry or seem to want to cry after a death that is significant to them. Grief, then, could be conceived as an instinctual response, shaped by evolutionary development. Perhaps animals grieve. Primates and birds display behaviours that seem similar to humans' in response to death and separation. Instinctual response in this sense is a meta-interpretative scheme programmed into our genetic inheritance, much as nest building or migration is hard-wired into birds. The response is aroused by the perception of specific situations (i.e., harm, threat, success or failure, and breeding opportunities). Culture, of course, influences how people appraise situations, yet similar perceptions of events trigger similar instinctual responses. A significant death, then, might be regarded as a universal trigger of grieving emotions, although which death is significant enough spark such a response depends on the value system of a particular culture. Universal instincts, then, might provide the basis for concepts that could explain behavior in all cultures. 
Some studies have also revealed that it is also not uncommon to feel withdrawn, depressed, insomniac, anti-social, tired or exhausted. In some cases one feels a loss of appetite, apathetic, at a loss, and disoriented. In other instances one is unmotivated and unable to complete day-to-day tasks including household chores or working. Some studies have also shown that in extreme instances, some mourners may actually be suicidal, paranoid, too exhausted to get out of bed, desperate, physically ill and mentally and emotionally unstable. However, each culture has its own way of coping with grief. While some may be sad, others view the death as a celebration of that person's life. Festive songs and music is played, while mourners (who are not actually mourning) take pride in knowing the deceased has "moved on" to another and possibly a better life.

\subsection{Theoretical Framework}

The model of grief based on the attachment instinct, propounded by John Bowlby and his followers, has generated a large body of research and advice for clinical practice. In this theory, a significant death triggers a response much like that which a child feels upon separation from his or her mother. First the child protests and tries to get back to the mother. Then the child despairs of returning to the mother but remains preoccupied with her. Finally the child loses interest in the mother and is emotionally detached from her upon her return. Grief after a significant death, this theory holds, follows the same preprogrammed sequence of behaviours. Attachment is instinctual behavior that has survival value because it keeps the child in close proximity to the mother for protection from predators. Humans are attached to individuals all through their lives. When they die, individuals experience separation and loss, and so must reorganize their attachments to match the new reality. From observation one knows that human children develop different styles of attachment, depending on the mother's bond with the child. Some bereavement research indicates that attachment styles in childhood predict bereavement style in adulthood. Attachment theorists have claimed that attachment is biological and, though influenced by culture, nonetheless functions similarly in all cultures; therefore, attachment theorists claim, the attachment instinct undergirds a cross-cultural model of grief.

Grief is conceptualised as an innate process that, if allowed to run its course, will bring the survivor to a new equilibrium in a changed world that no longer includes the dead person. In the constructivist model the purpose of grief is the construction of durable biographies-individual and social narratives - of the dead person and of the survivors that enable the living to integrate the dead into their lives. When an individual sees the world differently, he or she constructs a new narrative, a new biography of themselves and of the person who has died. In the constructivist model, the process by which people make sense of their world is social interaction. When something important happens in individuals' lives, they do not just think about it; they talk about it with others. Grief and mourning do not just happen inside a person; they happen in the interactions between people. In most cultures over human history, myth and ritual provide the inter-subjective space in which one can construct the meaning of the deceased's life, death, and influence over the survivors' lives. In contemporary Western culture, in which rituals and myths from earlier times have fallen into disuse, inter subjective space is characterized by informal verbal and nonverbal interaction aimed largely at communicating shared meaning. Often people see contemporary communities constructing their narrative by inventing new rituals that allow community members to feel a sense of togetherness.

Narratives, of course, are maintained within different kinds of social systems. Differences in mourning behaviour might be attributable to structural differences in societies. It appears that mourning in small, closely knit societies is different from mourning in large, more loosely knit societies in which primary membership is in the nuclear family. In small networks such as a rural village, members identify with people outside the nuclear family. When someone dies, people find substitutes for the deceased in their immediate social environment. For example, many adults already care for a child in a small network, so when a parent dies, other adults can easily move into the parent role. Death disrupts the social structure of small networks, so mourning rites focus on rehabilitating the damaged role system by reallocating roles. For example, when the elder dies, someone must be moved into the role of elder. In more complex, loosely knit networks, such as in an industrialized city, most individual deaths do not significantly affect the larger social system, so grief loses any larger social meaning and becomes a matter of individual family and psychic readjustment. 


\subsection{Some African Perspectives of Bereavement}

Africans believe that death completes an elaborate life cycle. It is a rite of passage that allows the person's spirit to travel on to its next life or world. However, this passage only happens if the person has a proper funeral if not; the deceased can come back and bring trouble for living family members. For example, when the person dies, it is customary to remove the body through a hole in the wall (feet pointing direction to cemetery), not the door, as the hole can be quickly closed back up again. The body is removed feet first and a zigzag path is taken to the cemetery or burial place so the "spirit" can find its way back to its residence. If a child dies, it is an especially grievous and evil time in African culture. Many people give their living children special names to ward off similar deaths. When a person dies, an animal is also killed as part of the ritual (and sometimes buried with the deceased), and all of his or her belongings are buried as well. African funerals are a time of solidarity. In some communities this means dancing and celebrations for everyone except the immediate family.

In South Africa, after a person dies in the house, all of the windows are covered in ash, and mirrors and other reflective objects are covered. All pictures are turned around and the bed is removed from the deceased room. Grieving women are to sit on the floor on mattresses. In some areas of South Africa, children and unmarried adults are not allowed to attend funeral services, which take place in the early morning hours. If they do attend, they are not allowed to partake in the ceremony. Also, there is a strict mourning period of up to one week. During this time, the bereaved family members stay at home, and have no social or sexual contact. They wear black clothing or cover their faces with black cloths, and some even shave their bodies, including all facial hair. Everything belonging to the deceased is considered "unclean" and should be washed and put away for the mourning period which traditionally can last up to one year.

\subsection{Zimbabwean Perspectives: Shona ways of Bereavement Counseling}

Shona practices in respect of dying and bereaved cannot be viewed separately from religious beliefs and spirituality. It is almost impossible to conceive of an entirely secular funeral in Shona society. As Hannan has put in Gerald 1977:-Foreword: "The foreigner as it seems to the Shona tends to regard religion as a separate compartment of life but for the Shona themselves, religion is an integral, all pervading elements of their way of living and thinking and acting'. The core of Shona religion is the belief in the creator God known as Mwari and in after life in which those who die are seen as having a different and continuing existence within the spirit world, but are still members of the extended family. Such spirit members known as Vadzimu are greatly respected and are seen as overseers of the moral behavior and welfare of the living family members. The relationship of ordinary people to Mwari is both distant and intimate .It is distant in that, requests to Mwari are usually mediated by Vadzimu who are seen as intermediaries between the living and Mwari. According to Hannan, in Gelfard (1977), the difference between a Shona adult's feelings towards his Vadzimu and his feelings towards his God is much the same as the difference between his feelings towards his father and his feelings towards his grandfather. He fears his father, while he respects his grandfather. This attitude to God finds expression on those occasions for example at a bereavement, when a show might scold the almighty with words he would never dare address to his mudzimu. From the above emerges a picture of a religious viewpoint in which there is a community of the living and the dead in the care of God but with the spirit elders very much monitoring and guiding the lives of the living where requests are made to Vadzimu for assistance, mediation or in reparation for wrong doings. These requests are always accompanied by gifts in the same way that a living messenger, if asked to mediate between living families would.

The process of burial aftermath then became the means of ensuring a smooth living membership of the family to membership as a spirit elder or vadzimu. Death is always considered to demand divination except in the case of an elderly person where people might say that, an old man died because he was tired or that the death was caused by the high god alone. Therefore, the time of death is not marked by grieving and loss but also by concerns about the cause of the death on a spiritual level. An illness/death is not a matter to be dealt with exclusively by the patient and his doctor, but is very much concern and even responsibility of the whole family. This viewpoint on illness means that, any seriously sick person is given a great deal of support from the family who in practical terms sees the illness as their illness. Elderly people quite often wish to talk about their impending departure and may summon the family to give instructions about the distribution of their possessions, which is usually done by the family according to customary guidelines rather than in accordance with written will. 
At the time of death of a member of a Shona family, all close relatives will have gathered to pay their last respect to the dying person. If the death is unexpected then relatives will gather as soon as possible, relatives, friends, neighbours and acquaintances will come to visit the bereaved, kubata maoko, literally to hold the hand of the mourning person ,but in fact to express condolences and give support to the bereaved for a prolonged period sometimes including an overnight stay or even longer. Relatives and friends who are women will remain in the house with the bereaved women at times crying, wailing, singing and dancing, while men gather outside around a fire. Grief is expressed in a very open way, both in respect of emotions and verbal sentiments felt by the bereaved. As each person arrives, especially close relatives, fresh weeping and wailing occurs and thus sharing of the grief occurs throughout the day or night. The repeated fresh weeping of a bereaved woman is psychologically healthy in that the sorrow is not at all repressed.

Most of the people prefer to bury their dead in the vicinity of their rural village, kumusha. The preference for a home burial is related to the need to ensure the smooth transition from the community of the living to a peaceful existence among the spirit elders who are part of the extended community of the living and the dead. There is a sense that a person buried in a rural home is not forsaken .There will be continued caring and respect articulated through a series of ritual events. When the burial takes place in a rural village, there are a number of ritual practices which allow the mourners to express their feelings and the departed to feel calm and peaceful. The detail of customary practices surrounding burial and its aftermath vary from area to area and culture to culture. When paying of respect is completed then it will be time to carry the body to the grave.

According to Chiremba and Rukuni (2002), cultural practices in Zimbabwe seem to promote bereavement counseling. The cultural practices include chisahwira. A person called sahwira will lead the whole process. The person will engage in various antics which make the family laugh. In this mourning style, friends of the dead /bereaved will dance, shout, sing and even dramatise the character of the dead. If the dead was a prostitute, a drunkard, a pastor, a business person or somebody respected in the community, they will dramatise what the deceased used to do. The laughter is a great antidote to the kind of heavy depressing atmosphere which can develop at funerals which is tiring and debilitating. The release of tension through laughter balances the atmosphere and gives the mourners renewed energy to complete the task of burial and reduce stress and emotions since the bereaved will even end up laughing thereby moving from a stressful moment to a light one which promotes health behaviour.

When bereaved, some people experience a delayed grieving or an aborted grieving. By wearing black clothes or bold head it reminds or helps stick into one's cognition that he/she is bereaved. It also help people in the community to console the bereaved and give him/ her the necessary support she might need .The African perspective is that of a system where by an individual should be treated in a system where if one part is disturbed, it affects the whole system. The deceased's clothes and properties are distributed to his/her relatives. This also helps the bereaved to understand that their loved one is gone forever; nothing of his possession is left. This process enhances acceptance. Although burial marks the physical separation from the deceased .It is by no means seen as final parting. Six months to a year or more later, cleansing by brewing beer (nyaradzo/kurowa guva) are some cultural rituals which mark the end of the grieving or mourning period. This ritual is actually performed to welcome the spirit of the deceased back into the home village. Bourdillion (1987) described the ceremony as a large number of relatives and friends of the deceased gathering, singing and dancing in honour of the spirit through most of one night there follows in the morning a procession to the grave or some other spot outside the homestead where various rituals are performed including generous libations of millet beer and the spirit is requested to come home, this is followed by further music and feasting in the homestead to welcome the spirit home. The ceremony allows relatives and friends to vividly remember the deceased and give vent to a variety of emotions surrounding the death.

Memorial service is both done by Christians and traditionalists as a way of marking the end of the mourning period. Black clothes are removed from the bereaved .This also help the bereaved to go through the process which lead to successful acceptance since they would have gone through the whole process of grieving. 


\section{RESEARCH Methodology}

The present study adopted the case study design which focused on one phenomenon that is, the effectiveness of the African bereavement counseling. The focus was on the Shona people of Zimbabwe which the researcher selected to understand in depth regardless of there being other cultures in Africa (Creswell, 2012). The case study was also used to gather directly from individuals for the purposes of studying their perceptions of the effectiveness of the African Bereavement Counselling $(\mathrm{ABC})$. The case study assisted in studying a single entity of the Zimbabwe Shona culture and enabled the researcher in the investigation, who are also stakeholders to the problem under study to be enmeshed in the study and obtain an in-depth insight into the activities of the African Bereavement Counselling a case of the Shona people in Zimbabwe.

\section{Participants and Selection of Participants}

The participants for the study were drawn from the five wards in Marondera Urban. These are situated in the main residential areas of town. The number of all prospective participants for the study was 5000 people. Out of 5000 people, a sample of 20 respondents was chosen through snowball sampling. The researcher identified a family that had suffered bereavement. The family became part of the sample. After obtaining data from the family, the researcher enquired from the respondent to identify another member in the locality who had been bereaved. The process continued until a sample of 20 had been interviewed. In order to accommodate a wide spectrum of respondents, all wards were accommodated in the study.

\section{RESEARCH INSTRUMENTS}

The present study adopted interviews as the instrument to facilitate the generation of data from the adolescents and parents while, pastors and councilors' views were extracted through the use of interviews. The process of data collection was carried out over a duration of two months stretching from April to June 2015, during which period the researchers had the privilege to interact with the respondents. After the samples had been drawn, a questionnaire with an introductory letter was mailed to all ordinary participating people. A total of 20 individuals were interviewed. All of the 7 members made up of the pastors and councilors were successfully interviewed.

\section{Presentation and Discussion of Findings}

The following discussion is based on the results which were obtained through data solicited through the use of questionnaires (for adolescents, people) as well as interviews (for pastors and councilors). All the 20(100\%) respondents returned the questionnaire and the 7(100\%) selected pastors and councilors were successfully interviewed. The majority, 45(90\%), of the respondents exhibited knowledge of what bereavement and grieving is and that children and women are the most affected by grief. Among the 10 members, 4(40\%) appeared not to be conversant with the knowledge of bereavement and grieving in Shona culture.

The majority, $40(80 \%)$ were in agreement with the African bereavement counseling techniques, $10(20 \%)$ remaining struggled to state whether the $\mathrm{ABC}$ techniques assist the bereaved to avoid grieving and promote behaviour change. One is, therefore, left wondering how these techniques could be effective. Out of the 50(100\%) respondents, 10(20\%) indicated that they knew there were ABC techniques but due to their religious beliefs they do not appreciate the styles for behavioral change since it's against their religious beliefs. The majority, 40(80\%) remarked that they were only aware of the existence of the African Bereavement Counseling techniques through socialisation and interaction within communities when there is death of a neighbour or relative. This result might have been influenced by the fact that prevalence of death due to HIV/AIDs and mixture of culture leading to some cross cultural issues in bereavement counseling. Thus, there is need to encourage people to conserve and appreciate their culture.

Cultural sensitivity is just as important during a mourning ceremony or funeral then it is at any other time. Just as everyone grieves differently, their beliefs and behaviors surrounding death are also not the same. Along with grieving, funerals are grand and supreme social events; they even replace Sunday worship services if necessary. Mourners dress in their best clothes to pay their respects to the grieving family. Mourners should not leave burial services before the last hymn is sung or the last shovel of dirt is tossed. Also, in order to keep the dead person's spirit away, each child member of the family is "passed" over the coffin as their last respect. Religious services are observed by family and 
friends, and on the final night, the duppy is bid farewell. Mourners play games, serve refreshments, prayers and stories are told, and hymns, accompanied by drums, are sung. The celebration continues until daylight.

The study established that adolescents are prone to social problems more than women followed by men. The social problems indicated include eating problems, loneliness ,trouble sleeping, role change ,overprotection of surviving caregivers, financial constraints ,bad relations with the deceased's relatives , loss of property among others. Therefore, African bereavement counselling is very powerful in assisting those bereaved.

On the effectiveness of the shona culture on counseling the bereaved, 20(40\%) of the respondents said 'NO' whilst 30(60\%) said 'YES'. This result indicates that the majority of the respondents have been assisted by the cultural techniques to change their behaviour. Those not in agreement could be explained by the fact that the respondents were of other religious beliefs and also behaviour change is a process. Four $(60 \%)$ out of 7 respondents interviewed pastors and councillors agreed that enough is being done to assist those bereaved whilst $3(40 \%)$ disagreed. This implies that a lot is being done to assist those bereaved. Prevalence of death is on the increase. This could have been promoted by an increase in HIV/AIDS related diseases.

While it may not always be noticeable, everyone grieves the loss of a loved one. Some cultures may be more open about it and others only allow grieving to happen in silence and solitude. But everyone grieves.

Evidence in the study suggests that $\mathrm{ABC}$ techniques by shona people on counseling the bereaved are reaching the intended beneficiaries and are being assisted towards behaviour change. However, what is important to remember is that sometimes, grief can be overwhelming and if it does get out of hand or control, there is professional help available.

\section{CONCLUSIONS AND IMPLICATIONS FOR ODL INSTITUTIONS}

The study established that people grieve and when they grieve they are psychologically, socially and physically affected by grief. The study noted that grieving people were affected with long term psychological consequences such as depression, anxiety, past traumatic stress disorder, behaviour problems, suicidal ideation and reduced psychological functioning. The study also established that African Bereavement counseling techniques are very effective in counseling the bereaved. In the Shona culture such grieving styles can make one's burden easy. It was also established that the Shona cultural ways of assisting the bereaved are not enough as some of the techniques used in hastening recovery were often retrogressive. Taking cognisance of the view that death is devastating on both the dying and the bereaved. There is need for bereavement intervention programmes and ODL institutions, due to their geographical advantage, can be able to make provisions or counselling for those who suffer bereavement. The Zimbabwe Open University, for example, through the Department of Counselling in the Faculty of Applied Social Sciences, can play a leading role through Programme Coordinators in the ten geo-political provinces can study the bereavement practices in their areas and find out ways of assisting those in moaning. ZOU is already heavily decentralised unlike other organisations or associations. Thus, the already existing human and infrastructural resources in the regional centres and districts can be utilised by ZOU unlike other institutions that need to decentralize so as to make themselves accessible to those bereaved. However, counselors should be multicultural when dealing with grieving issues. It is more therapeutic to help a client in his /her frame of reference thus in client's cultural setting. These counselors should use /adopt the African bereavement counseling techniques to enhance an effective therapeutic environment. As long as the severity of the problem is denied or minimised and the aspects are not held up to the light of the day or dealt with at the roots, it will continue to manifest itself in a multiple expressions of toxicity, thus confronting the reality of bereavement facilitates resolution of grief. Hence ZOU can play a role which could see the institution realising a major boost in terms of popularity which might translate to huge enrolment figures at the same time providing the much needed bereavement counseling in the community for free. 


\section{REFERENCES}

Allumbach, D.L. \& Hoyt, W.T. (1999). 'Effectiveness of grief therapy: A meta-analysis', 'Journal of Counseling Psychology 46, 370-380.

Bourdillon M. (1987). The Shona People, Mambo Press, Gweru.

Bouton, B.L., (1996), 'The interdisciplinary bereavement team. Defining and directing appropriate bereavement care', The Hospice Journal 11(4), 15-24.

Bowlby, J. (1980). Attachment and loss. Loss: Sadness and Depression, vol. 3, Hogarth, London.

Bendann, Effie. (1939). Death Customs: An Analytical Study of Burial Rites. London: Kogan Paul.

Clare, A. (1995). "Death and Dying." In Charles Kean ed., Death and Dying. Cork, Ireland: Mercier Press.

Crissman, J. K. (1994). Death and Dying in Central Appalachia: Changing Attitudes and Practices. Urbana: University of Illinois Press.

Cooper, M.G. \& Lesser, J.G., (2002). Clinical social work practice. An integrated approach, Allyn \& Bacon, Boston.

Grainger, R. (1998). The Social Symbolism of Grief and Mourning. London: Kingsley.

Hockey, J. (1993)."The Acceptable Face of Human Grieving? The Clergy's Role in Managing Emotional Expression in Funerals." In D. Clark ed., The Sociology of Death. Oxford: Blackwell.

Creswell, J.W. (2003). Research design. Qualitative, quantitative, and mixed methods Approaches, 2nd ed., Sage Publications, Thousand Oaks.

R.O. Hansson, W. Stroebe \& H. Schut (eds.), Handbook of bereavement research. Consequences, coping and care, pp. 647-669, American Psychological Association, Washington, DC.

Gelfand, M. (1997). The Spiritual Beliefs of the Shona. Mambo Press, Gweru.

Kubler -Ross, E. (1969). On Death and dying, Macmillan Press, New York

Robbins, L., (2000). 'Cultural attitudes towards death and dying: A South African perspective', Palliative Medicine 14,437-439.

Jordan, J.R. \& Niemeyer, R.A., (2003). 'Does grief counseling work?' Death studies 27, 765-786.

Schut, H., Stroebe, M.S., van den Bout, J. \& Terheggen, M., (2001), ' The efficacy of bereavement interventions. Determining, who benefits', in M.S. Stroebe, R.O. Hansson, W. Stroebe \& H. Stroebe, M. \& Schut, H., 1999, 'The dual process model of coping with bereavement. Rationale and description', Death Studies 23, 197-224.

\section{AUTHORS' BIOGRAPHY}

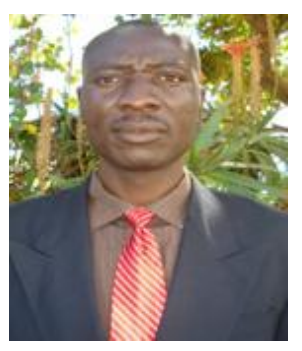

Richard BUKALIYA, is a Professor teaching at the Zimbabwe Open University in the Faculty of Arts and Education. He is the Regional Programme Coordinator in the Department of Teacher Development. His research interests include issues in Distance Education and Primary and Secondary education. The researcher has, to date, published several research articles in several international journals. He has presented papers at conferences locally and internationally. $\mathrm{He}$ is on the review boards of several international research journals which include the International Journal of Social Sciences and Education (IJSSE), The International Journal of Educational Research (JER), Greener Journals and the Global Research Journal of Education.

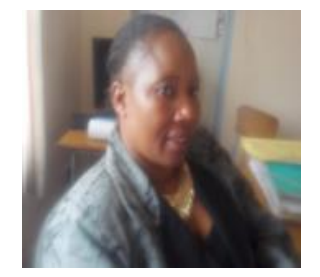

Shillah Rugonye, is a lecturer at Zimbabwe Open University at Mashonaland East Regional Campus, Faculty of Applied Social Sciences in the Department of Counselling. She is a holder of Executive Masters in Peace, Leadership and Governance, Msc Counselling, Bsc Counselling, Diploma in Education and Certificate in Systemic Counselling. 